\title{
Bronchial reactivity indices are determinants of health-related quality of life in patients with stable asthma
}

\author{
Carolina Cisneros, ${ }^{1}$ Francisco García-Río, ${ }^{2}$ Delia Romera, ${ }^{2}$ Carlos Villasante, ${ }^{2}$ \\ Rosa Girón, ${ }^{1}$ Julio Ancochea ${ }^{1}$
}

- Additional tables are published online only. To view these files please visit the journal online (http://thorax.bmj. com).

'Servicio de Neumología, Hospital Universitario La Princesa, Instituto de Investigación Sanitaria Hospital Princesa, Madrid, Spain ${ }^{2}$ Servicio de Neumología, Hospital Universitario La Paz, IdiPAZ, Madrid, Spain

\section{Correspondence to} Carolina Cisneros, Servicio de Neumología, Hospital La Princesa, c/ Diego de León no. 62, Madrid 28006, Spain; carol9199@yahoo.es

Received 24 February 2010 Accepted 25 May 2010

\begin{abstract}
Background $A$ very weak relationship has been reported between the health-related quality of life (HROL) of patients with asthma and their degree of airway hyper-responsiveness (AHR), evaluated in terms of sensitivity. However, this relationship still has not been sufficiently explored for bronchial reactivity indices.

Objectives To analyse the relationship between bronchial reactivity and sensitivity with the HROL of patients with stable asthma, identifying the functional parameters that determine HROL.
\end{abstract}

Methods In 103 consecutive patients with stable asthma, HROL was evaluated using the Asthma Quality of Life Questionnaire (AOLO). Patients underwent spirometry and non-specific bronchial provocation with methacoline. Sensitivity $\left(\mathrm{PD}_{20}\right)$ and reactivity (dose-response slope (DRS), continuous index of responsiveness (CIR) and bronchial reactivity index (BRI)) of the dose-response curve were analysed.

Results BRI presented significant differences with different degrees of asthma severity. Although patients with AHR showed poorer quality of life than patients without AHR, the AOLO total score was not related to $\mathrm{PD}_{20}$ but rather to DRS $(r=-0.784), \mathrm{CIR}(\mathrm{r}=-0.712)$ and $B R I(r=-0.776)$. The indices of bronchial reactivity reached a negative correlation with all the domains of the AOLO. In a multiple linear regression model, BRI, DRS, FIV ${ }_{1}$ (forced inspiratory volume in $1 \mathrm{~s}$ ) and VCIN (inspiratory vital capacity) were identified as independent predictors of the AOLO total score $\left(r^{2}=0.742, p<0.001\right)$.

Conclusion In patients with stable asthma, bronchial reactivity is associated with HROL. This could justify incorporating bronchial reactivity indices in bronchial provocation analyses.

\section{INTRODUCTION}

Airway hyper-responsiveness (AHR) constitutes the most relevant physiological disorder of asthmatic disease, and has therefore always been present in its definition. ${ }^{1}$ Despite the importance of physiological measures in evaluating the progression of asthma and its response to different treatments, in the last few years the impact of the disease on patient lifestyle, or health-related quality of life (HRQL), has become increasingly important. The HROL is determined by the patient's judgement of the effects that the disease and its treatment may have had on his/her everyday lifestyle. ${ }^{2}$

Previous studies have demonstrated the limited correlation that exists between the measures traditionally used to evaluate the degree of control of patients with asthma (bronchial obstruction, nocturnal and diurnal symptoms, use of rescue medication) and HROL. ${ }^{3-6}$ Although this clinical-functional dissociation has been justified by the lack of precision inherent in determining HROL as well as asthma symptoms themselves, it has also been proposed that the HROL be considered a component of the state of health in asthma, and should therefore form part of its systematic evaluation. ${ }^{7}$ It has been reported, for example, that a patient can experience important benefits in his/ her HROL without there being apparent changes in these other clinical indices. ${ }^{89}$

To date, few studies have analysed the relationship between the degree of AHR and $\mathrm{HROL}^{7-14}$ and, with the exception of one, ${ }^{11}$ all have considered AHR in terms of sensitivity or threshold $\left(\mathrm{PD}_{20}\right.$ or $\left.\mathrm{PC}_{20}\right)$. This type of analysis of the bronchial provocation dose-response curve reflects the dose threshold necessary to trigger bronchoconstriction, but it does not evaluate the intensity with which it is produced. ${ }^{15} 16$

In order to evaluate AHR severity more adequately, we proposed considering the slope of the dose-response curve as an indicator of airway reactivity in the presence of a bronchoconstricting agent. ${ }^{17} 18$ Unlike the sensitivity analysis, bronchial reactivity seems to more adequately reflect the severity of the response, as it assesses the intensity of the bronchoconstriction. ${ }^{17}{ }^{18}$ In addition, it has been shown to be more useful in identifying patients with asthma ${ }^{19}$ and in maintaining a better relationship with the degree of oxidative stress of these patients. ${ }^{20}$

We therefore hypothesise that bronchial reactivity could show a better relationship with the HROL of patients with asthma. Therefore, our objective was to identify those functional parameters that are independent determinants of HROL in patients with stable asthma.

\section{METHODS \\ Study subjects}

We consecutively selected patients with a diagnosis of asthma established at least 6 months earlier, following the GINA (Global Initiative for Asthma) criteria, ${ }^{21}$ who had been referred for non-specific bronchial provocation testing to the Pulmonology Units at La Princesa and La Paz University Hospitals (Madrid, Spain) from October 2005 to May 2007. Exclusion criteria included the existence of another concurrent disease (except atopy, rhinoconjunctivitis, nasal polyposis or intolerance to non-steroidal 
anti-inflammatory drugs), an asthmatic exacerbation within the previous 3 months, use of oral glucocorticoids, a contraindication for performing the methacholine bronchial challenge and the inability to comprehend or carry out the study procedures.

All patients gave their informed consent, and the study was approved by the Clinical Research Ethics Committees of both centres.

\section{Clinical evaluation and quality of life}

We registered either the presence or lack of symptoms (dyspnoea, cough and wheezing) during the previous 4 weeks, current medication, time since diagnosis of asthma, results from skin prick tests for immediate hypersensitivity, as well as the number of exacerbations and hospital admittances over the previous 12 months. The patients were classified into four categories according to asthma severity (level of symptoms, airflow limitation and lung function variability), taking into account the treatment dose and following the recommendations of the GINA 2002: intermittent, mild persistent, moderate persistent or severe persistent. ${ }^{21}$

All patients were asked to answer the self-administered, validated Spanish version of the Asthma Quality of Life Questionnaire (AOLQ) by Juniper. ${ }^{22}$ It consists of four domains: 'symptoms' (12 items), 'activity limitation' (11 items), 'emotional function' (5 items) and susceptibility to 'environmental exposure' (4 items). Domain scores were calculated as the average of the items within each domain and presented on a Likert-type scale varying from 1 (most severe impairment) to 7 (no impairment).

\section{Lung function tests}

Lung function data were obtained at both centres at approximately the same time during the day (11:00 to 13:00), using the same equipment, MasterScreen Pneumo version 4.2 (VIASYS Healthcare, Hoechberg, Germany). Spirometry was performed according to American Thoracic Society recommendations, ${ }^{23}$ and the predicted values of the European Coal and Steel Community were used. ${ }^{24}$ To assess the inspiratory parameters, measurements were repeated until the differences in forced inspiratory volume in $1 \mathrm{~s}\left(\mathrm{FIV}_{1}\right)$ were $<5 \%$ relative to the higher value. From two acceptable manoeuvres (difference $<5 \%$ ), the highest value of $\mathrm{FIV}_{1}$ was chosen for analysis.

A standardised dosimeter technique was used for methacholine challenge. ${ }^{25}$ A bronchial aerosol provocation system (APS, Jaeger, Würzburg, Germany) with a Medic Aid SideStream nebuliser (Medic-Aid Ltd, Bognor Regis, UK) was used for this procedure. The nebuliser was calibrated to produce an output of $160 \mathrm{mg} / \mathrm{ml}$, with an airflow rate of $100 \mathrm{ml} / \mathrm{s}$. A flow sensor in the expiratory port triggers a solenoid which exposes the nebuliser to compressed air at $138 \mathrm{kPa}$ (20 psi) for $\sim 0.6 \mathrm{~s}$, to give a calibrated output per puff of $9.0 \mu \mathrm{l}$. The nebuliser generates heterodisperse droplets with a median aerodynamic mass diameter of $0.5-4 \mu \mathrm{m}$.

Each subject was instructed to inhale the aerosols by taking slow, deep breaths from functional residual capacity to inspiratory capacity without breath holding. The first aerosol was $0.9 \%$ saline followed by doubling doses of methacholine chloride from 0.0013 to $9.9 \mu \mathrm{mol}$. A 3 min interval was allowed before each dose increment. Forced expiratory volume in $1 \mathrm{~s}\left(\mathrm{FEV}_{1}\right)$ was measured by a MasterScreen Pneumo 2 min after each dose, and the highest of three acceptable measurements within $100 \mathrm{ml}$ was retained to create dose-response curves. The test was discontinued when there was a fall in $\mathrm{FEV}_{1}$ of $\geq 20 \%$ compared with the control inhalation $(0.9 \%$ saline solution) or until the maximal dose was inhaled.

Table 1 General characteristics of the patients

\begin{tabular}{|c|c|c|c|c|c|c|}
\hline & $\begin{array}{l}\text { Total } \\
(n=103)\end{array}$ & $\begin{array}{l}\text { Intermittent } \\
\text { asthma }(n=22)\end{array}$ & $\begin{array}{l}\text { Mild persistent } \\
\text { asthma }(n=45)\end{array}$ & $\begin{array}{l}\text { Moderate persistent } \\
\text { asthma }(n=32)\end{array}$ & $\begin{array}{l}\text { Severe persistent } \\
\text { asthma }(n=4)\end{array}$ & p Value \\
\hline Females, n (\%) & $77(75)$ & $18(82)$ & $36(80)$ & $19(59)$ & $4(100)$ & 0.212 \\
\hline Age, years & $41 \pm 16$ & $36 \pm 20$ & $40 \pm 16$ & $47 \pm 13$ & $26 \pm 1$ & 0.014 \\
\hline Current smoker, n (\%) & $15(15)$ & $4(18)$ & $10(22)$ & $1(3)$ & $0(0)$ & 0.110 \\
\hline Atopy, n (\%) & $54(53)$ & $15(68)$ & $24(56)$ & $11(34)$ & $4(100)$ & 0.017 \\
\hline Years since diagnosis & $9 \pm 8$ & $10 \pm 11$ & $6 \pm 6$ & $11 \pm 9$ & $11 \pm 6$ & 0.083 \\
\hline Hospitalisations last year & $0.3 \pm 0.8$ & $0.2 \pm 0.6$ & $0.0 \pm 0.0$ & $0.6 \pm 1.2$ & $0.5 \pm 0.6$ & 0.003 \\
\hline Long-acting $\beta$-agonist, $\mathrm{n}$ (\%) & $61(59)$ & $4(18)$ & $24(53)$ & $29(91)$ & $4(100)$ & $<0.001$ \\
\hline Inhaled corticosteroids, n (\%) & $81(79)$ & $4(18)$ & $41(91)$ & $32(100)$ & $4(100)$ & $<0.001$ \\
\hline Leukotriene receptor antagonist, $\mathrm{n}(\%)$ & $18(17)$ & $4(18)$ & $6(13)$ & $8(25)$ & $4(100)$ & 0.449 \\
\hline Antihistamine, $\mathrm{n}(\%)$ & $4(4)$ & $2(9)$ & $0(0)$ & $2(6)$ & $0(0)$ & 0.255 \\
\hline $\mathrm{FEV}_{1} / \mathrm{FVC}$ & $0.81 \pm 0.07$ & $0.84 \pm 0.09$ & $0.81 \pm 0.07$ & $0.79 \pm 0.06$ & $0.81 \pm 0.05$ & 0.132 \\
\hline PEF, I/s & $6.95 \pm 1.70$ & $7.34 \pm 1.99$ & $7.10 \pm 1.58$ & $6.55 \pm 1.65$ & $6.29 \pm 1.32$ & 0.281 \\
\hline $\mathrm{FEF}_{75 \%,}, \mathrm{l} / \mathrm{s}$ & $3.03 \pm 2.70$ & $2.72 \pm 2.51$ & $3.85 \pm 3.11$ & $2.10 \pm 1.94$ & $2.98 \pm 1.37$ & 0.038 \\
\hline $\mathrm{FEF}_{50 \%,}, \mathrm{l} / \mathrm{s}$ & $3.19 \pm 1.56$ & $3.72 \pm 2.12$ & $3.35 \pm 1.32$ & $2.53 \pm 1.23$ & $3.73 \pm 1.82$ & 0.026 \\
\hline $\mathrm{FEF}_{25 \%,}, \mathrm{l} / \mathrm{s}$ & $3.71 \pm 2.48$ & $4.71 \pm 2.63$ & $3.28 \pm 2.21$ & $3.58 \pm 2.47$ & $4.07 \pm 3.80$ & 0.160 \\
\hline $\mathrm{FEF}_{25-75 \%,} \mathrm{l} / \mathrm{s}$ & $2.63 \pm 1.56$ & $3.33 \pm 2.28$ & $2.72 \pm 1.20$ & $1.99 \pm 1.19$ & $3.04 \pm 1.42$ & 0.015 \\
\hline VCIN, litres & $3.56 \pm 0.91$ & $3.60 \pm 0.91$ & $3.73 \pm 0.98$ & $3.31 \pm 0.78$ & $3.16 \pm 0.00$ & 0.273 \\
\hline IC, litres & $2.67 \pm 0.59$ & $2.55 \pm 0.42$ & $2.65 \pm 0.60$ & $2.81 \pm 0.66$ & $2.32 \pm 0.00$ & 0.491 \\
\hline FIV $_{1}$, litres & $3.24 \pm 0.84$ & $3.37 \pm 0.92$ & $3.35 \pm 0.83$ & $3.03 \pm 0.83$ & $2.90 \pm 0.20$ & 0.259 \\
\hline
\end{tabular}

$\mathrm{p}$ Values were tested by analysis of variance with the Bonferroni posthoc test if the variable is stated as mean (SD) or by $\chi^{2}$ test if the variable is stated as $\mathrm{n}$ (\%).

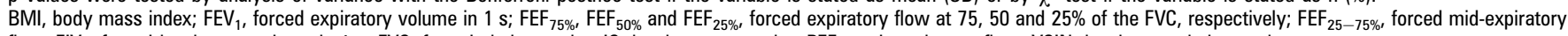
flow; FIV , forced inspiratory volume in $1 \mathrm{~s}$; FVC, forced vital capacity; IC, inspiratory capacity; PEF, peak expiratory flow; VCIN, inspiratory vital capacity. 
Dose-response curves were plotted for each challenge test as the percentage fall in $\mathrm{FEV}_{1}$ against the dose of methacholine on a log scale and were characterised by their sensitivity (dose of methacholine that produced a $20 \%$ fall in $\mathrm{FEV}_{1} ; \mathrm{PD}_{20}$ ) and their slope. When $\mathrm{FEV}_{1}$ had fallen by $\geq 20 \%$ from the postdiluent baseline value, the challenge was considered positive and $\mathrm{PD}_{20}$ was determined by linear extrapolation on a semi-logarithmic scale. Dose-response slope (DRS) was summarised as the expression: percentage decline in $\mathrm{FEV}_{1}$ /dose, where percentage decline in $\mathrm{FEV}_{1}$ was defined as the decline in $\mathrm{FEV}_{1}$ from the postdiluent baseline values after the final methacholine dose was administered, and dose was defined as the final cumulative dose administered. ${ }^{17}$ The continuous index of responsiveness (CIR) was determined as the logarithm of the percentage decline from the postdiluent baseline $\mathrm{FEV}_{1}$ after the last dose of methacholine per unit dose of methacholine. ${ }^{18}$ Finally, the bronchial reactivity index (BRI) was defined as the log of the percentage decline in $\mathrm{FEV}_{1} / \log$ final methacholine dose after adding 10 to eliminate negative values. ${ }^{18}$

\section{Statistical analysis}

Based on the correlation coefficient detected between the total score of the AOLQ and the BRI in a previous pilot study $(n=15$, $\mathrm{r}=0.33$ ), it was determined that the sample necessary in order to detect a significant relationship using a two-sided one-sample correlation test, with an $\alpha$ risk of 0.05 , a $\beta$ risk of 0.10 and an estimated loss of $10 \%$, should include 103 subjects.

Normality in the distribution of the data for each variable was explored using Skewness-Kurtosis tests. Values are expressed as mean $\pm S D$, or percentage. All statistical tests were two sided. Differences between groups were analysed by the $\chi^{2}$ test (categorical variables), Student $t$ test (ordinary or non-normal metric variables) and analysis of variance with the Bonferroni posthoc test (normally distributed metric variables).

The relationships between variables were determined using the Pearson correlation. The assumptions of linearity and distributional normality were controlled for all variables. A histogram of residuals and a normal probability plot of residuals were used to test for normality. Homoscedasticity was explored by scatter plots of the standardised residuals on the standardised predicted values and by the Levene test for equality of variances. When heteroscedasticity was suspected, regression coefficients were computed using weighted least squares.

Age, sex, body mass index (BMI), years since diagnosis, smoking status (pack-years), atopy, employment status and significant contributors were then introduced in a stepwise multiple linear regression analysis to identify independent determinants of the AOLO total score. In the multiple linear regression analysis, predictor variables were retained only if their addition significantly improved $(p<0.05)$ the fraction of explained variability $\left(\mathrm{r}^{2}\right)$. Other aspects explored included residual $\mathrm{SD}$, changes in the distribution of the residuals and the homogeneity of the variance over the predictors.

Statistical significance was assumed for $\mathrm{p}<0.05$. All analyses were performed using the Statistical Package for the Social Sciences, version 13.0 software (SPSS, Chicago, Illinois, USA).

\section{RESULTS}

A total of 103 patients were studied, 77 of whom were women and 26 men, with an age (mean \pm SD) of $41 \pm 16$ years (range $16-71)$, and most of whom were actively employed (55\%). The disease had been diagnosed $9 \pm 8$ years earlier (range $0.5-38$ ), with less than one exacerbation in the previous year $(0.7 \pm 0.9)$ and with hardly any hospital admittances for asthma in the previous 12 months $(0.3 \pm 0.8)$ (range $0-5)$. Asthma severity showed a rather homogenous distribution, 22 patients presenting intermittent asthma, 45 with persistent mild asthma, 32 with moderate persistent asthma and only 4 with severe persistent asthma (table 1).

Table 2 presents the total score and that of the different dominions of the AOLO according to the different severity levels of the disease, as well as the results of the methacholine challenge, which was positive in 69 cases (67\%). No significant differences were detected in bronchial sensitivity, while the BRI was the only bronchial reactivity index that showed significant differences according to asthma severity. The AOLO only reached significant differences in the 'activity limitation' domain among patients with mild persistent asthma and moderate persistent asthma.

The clinical parameters showed a poor relationship with the results of the bronchial provocation (see table 1 online). Only the number of exacerbations in the previous year showed a significant correlation with CIR and BRI. Likewise, CIR showed a significant correlation with BMI and the number of hospitalisations in the previous year. In the asthma patient group as a whole, HRQL evaluated through AOLO reached a limited relationship with the clinical evolution variables and with the majority of the spirometric parameters.

There was also a weak but significant relationship among practically all the domains of the questionnaire and the parameters corresponding to forced inspiration (see table 2 online).

Table 2 Bronchial sensitivity and reactivity indices and health-related quality of life in patients with asthma*

\begin{tabular}{|c|c|c|c|c|c|c|}
\hline & Total & $\begin{array}{l}\text { Intermittent } \\
\text { asthma }\end{array}$ & $\begin{array}{l}\text { Mild persistent } \\
\text { asthma }\end{array}$ & $\begin{array}{l}\text { Moderate persistent } \\
\text { asthma }\end{array}$ & $\begin{array}{l}\text { Severe persistent } \\
\text { asthma }\end{array}$ & p Value \\
\hline $\mathrm{PD}_{20}, \mu \mathrm{mol}$ & $3.11 \pm 2.76$ & $3.81 \pm 2.34$ & $2.69 \pm 2.71$ & $3.56 \pm 3.21$ & $2.29 \pm 0.40$ & 0.517 \\
\hline \multicolumn{7}{|l|}{ Bronchial reactivity indices } \\
\hline $\mathrm{DRS}, \% / \mu \mathrm{mol}$ & $5.19 \pm 5.82$ & $5.99 \pm 8.42$ & $4.46 \pm 4.13$ & $5.14 \pm 5.93$ & $9.31 \pm 2.46$ & 0.376 \\
\hline CIR & $0.44 \pm 0.58$ & $0.37 \pm 0.63$ & $0.49 \pm 0.51$ & $0.36 \pm 0.64$ & $0.96 \pm 0.12$ & 0.218 \\
\hline $\mathrm{BRI}$ & $12.7 \pm 3.1$ & $12.4 \pm 3.0$ & $12.1 \pm 2.2$ & $13.3 \pm 4.0$ & $17.3 \pm 0.7 \dagger \neq$ & 0.008 \\
\hline \multicolumn{7}{|l|}{ AOLO } \\
\hline Symptoms & $5.78 \pm 0.85$ & $5.83 \pm 0.94$ & $5.90 \pm 0.57$ & $5.72 \pm 1.06$ & $4.79 \pm 0.24$ & 0.086 \\
\hline Activity limitation & $5.87 \pm 0.82$ & $5.96 \pm 0.93$ & $6.11 \pm 0.42$ & $5.57 \pm 1.05 \S$ & $5.14 \pm 0.05$ & 0.008 \\
\hline Emotional function & $6.03 \pm 0.92$ & $5.80 \pm 0.80$ & $6.17 \pm 0.66$ & $6.05 \pm 1.26$ & $5.80 \pm 0.00$ & 0.465 \\
\hline Environmental exposure & $5.87 \pm 0.78$ & $5.68 \pm 1.17$ & $6.07 \pm 0.58$ & $5.81 \pm 0.67$ & $5.25 \pm 0.29$ & 0.080 \\
\hline Total & $5.86 \pm 0.73$ & $5.85 \pm 0.83$ & $6.04 \pm 0.42$ & $5.73 \pm 0.92$ & $5.13 \pm 0.14$ & 0.052 \\
\hline
\end{tabular}

*Data are mean \pm SD

Comparisons between groups: $\dagger p=0.020$ vs intermittent asthma; $\neq p=0.007$ vs mild persistent asthma; $\$ p=0.024$ vs mild persistent asthma.

$\mathrm{AQLQ}$, Asthma Quality of Life Questionnaire; BRI, bronchial reactivity index; CIR, continuous index of responsiveness; $\mathrm{DRS}$, dose-response slope; $\mathrm{PD}_{20}$, dose of methacholine that produced a $20 \%$ fall in forced expiratory volume at $1 \mathrm{~s}$. 


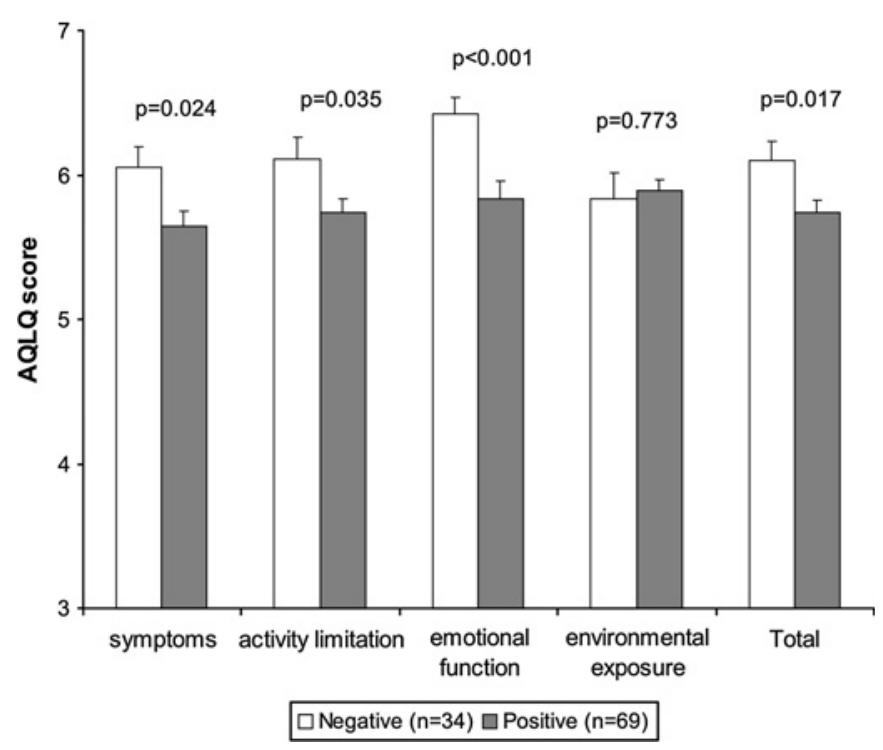

Figure 1 Comparison of Asthma Quality of Life Questionnaire (AOLO) score according to the response to methacholine bronchial challenge. Vertical error bars are the SEM.

When the AOLO scores were compared for conventional response to methacholine, we observed that the patients with a positive bronchial provocation test (fall in $\mathrm{FEV}_{1} \geq 20 \%$ ) presented poorer HRQL, both in the total score of the AOLQ and in most of its domains (figure 1). Table 2 online also shows the correlation analysis between the sensitivity indices $\left(\mathrm{PD}_{20}\right)$ and bronchial reactivity (DRS, CIR and BRI) to methacholine and the HROL of all the patients with asthma (figure 2). While $\mathrm{PD}_{20}$ only reached a significant relationship with the 'environmental exposure' domain of the AOLQ, the three indices of bronchial reactivity maintained a significant relationship with all the domains of the HROL evaluated.

All the variables that in the univariate analysis showed a relationship with the total score of the AOLO were entered into the stepwise multiple linear regression analysis. The model obtained identified BRI, DRS, FIV 1 and VCIN (inspiratory vital capacity) as independent predictor variables for the AOLO total score $\left(\mathrm{r}^{2}=0.742, \mathrm{p}<0.001\right)$ (table 3 ).

\section{DISCUSSION}

Our study shows that bronchial reactivity is a prominent determinant of the HROL of patients with stable asthma, which also identifies the contribution of some inspiratory volumes. It confirms that the indices of bronchial reactivity to methacoline better correlate with HROL than sensitivity, expressed in terms of $\mathrm{PD}_{20}$. In addition, bronchial reactivity indices are different at the different levels of asthma severity, which does not happen with $\mathrm{PD}_{20}$.

Previous studies had already reported a lack of relationship between the clinical state of patients with asthma and AHR. ${ }^{26}{ }^{27}$ Our patients also did not show differences in bronchial sensitivity $\left(\mathrm{PD}_{20}\right)$ among the different asthma severity levels. However, the BRI presented a differential behaviour among persistent severe, moderate and mild asthma. This finding concurs with the suggestion that bronchial reactivity better evaluates the intensity of bronchoconstriction and, therefore, asthma severity. ${ }^{28}$ Moreover, it has been proposed that bronchial reactivity could be considered a marker of airway inflammation sensitive to steroid treatment. ${ }^{29}$ In fact, a previous study has reported that the BRI is related to the amount of eosinophils in the peripheral blood in subjects with AHR as well as in those without. 19

The finding of a poorer HROL in those patients with asthma with AHR concurs with the reports of other authors.
Figure 2 Relationship between total Asthma Quality of Life Questionnaire (AQLO) score with $\mathrm{PD}_{20}(\mathrm{~A})$, the dose-response slope (DRS) (B), the continuous index of responsiveness $(\mathrm{CIR})(\mathrm{C})$ and the bronchial reactivity index (BRI) (D).
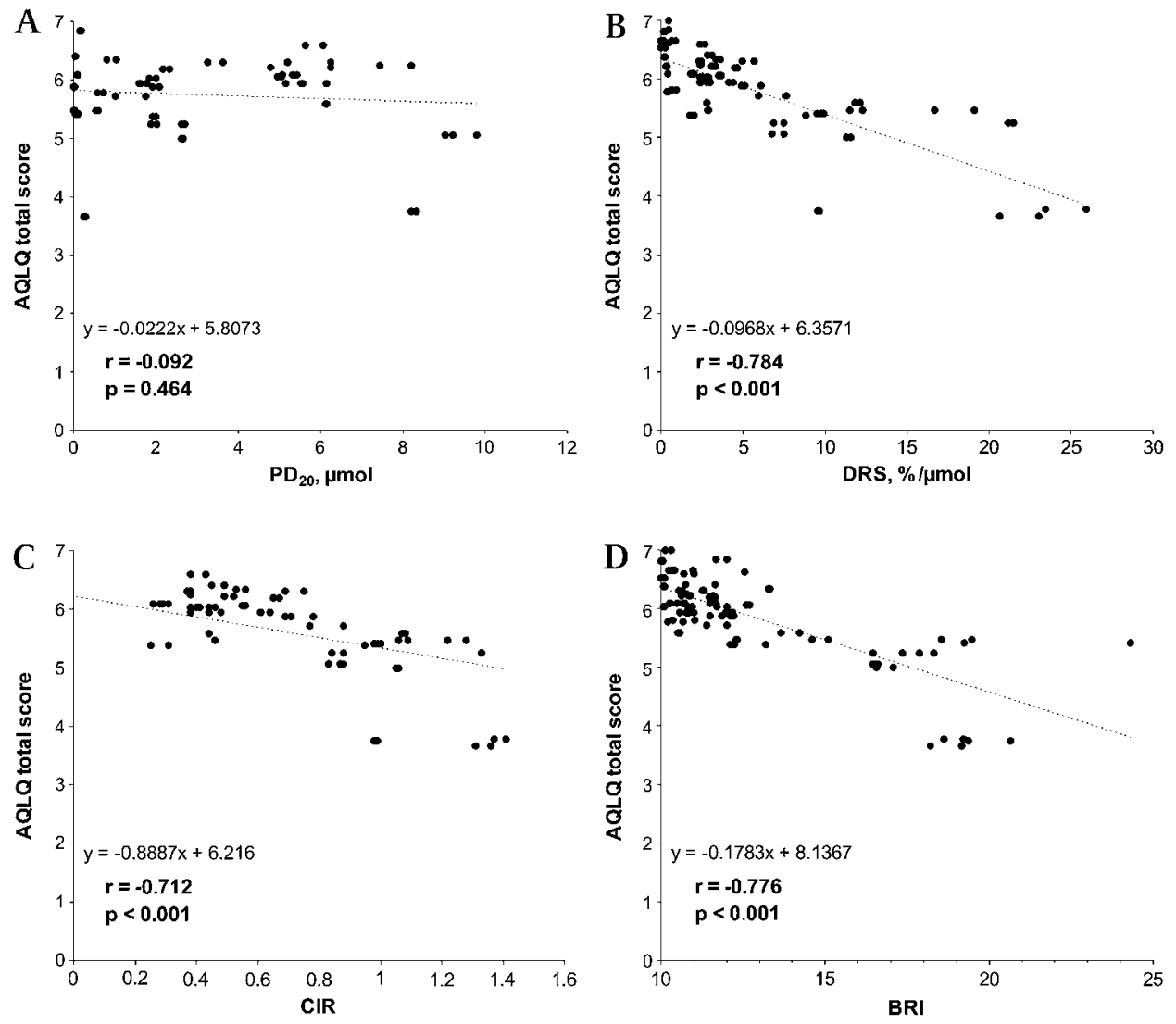
Table 3 Independent predictors of AOLO total score in a multivariate linear regression analysis

\begin{tabular}{|c|c|c|c|c|c|c|c|c|}
\hline & \multicolumn{2}{|c|}{$\begin{array}{l}\text { Unstandardised } \\
\text { regression } \\
\text { coefficients }\end{array}$} & \multicolumn{2}{|c|}{$95 \% \mathrm{Cl}$ for $\mathrm{B}$} & \multirow{2}{*}{$\begin{array}{l}\text { Standardised } \\
\text { regression } \\
\text { coefficients } \\
\text { B } \\
\end{array}$} & \multirow[b]{2}{*}{ p Value } & \multirow[b]{2}{*}{$\mathrm{R}^{2}$} & \multirow[b]{2}{*}{$R^{2}$ change } \\
\hline & $\bar{B}$ & SE & Lower limit & Upper limit & & & & \\
\hline BRI & -0.090 & 0.021 & -0.133 & -0.047 & -0.412 & $<0.0001$ & 0.596 & - \\
\hline $\mathrm{DRS}, \% / \mu \mathrm{mol}$ & -0.046 & 0.013 & -0.071 & -0.021 & -0.357 & 0.0004 & 0.670 & 0.075 \\
\hline FIV $_{1}$, litres & 0.513 & 0.141 & 0.231 & 0.795 & 0.664 & 0.005 & 0.712 & 0.042 \\
\hline
\end{tabular}

AQLQ, Asthma Quality of Life Questionnaire; BRI, bronchial reactivity index; DRS, dose-response slope; FIV , forced inspiratory volume in 1 s; VCIN, inspiratory vital capacity.

Riccioni et al ${ }^{10}$ observed statistically significant differences in the total score and in each of the domains of the AOLO between those patients with and those without AHR. They did not, however, evaluate the severity of the asthma, using instead a limited diagnostic criterion (increase in peak expiratory flow (PEF) after bronchodilator $>15 \%$ ), nor did they take into consideration the treatment, and only $51 \%$ positive bronchial provocations were registered.

More recently, Porsbjerg et al ${ }^{11}$ reported that patients with moderate to severe asthma and AHR had a poorer quality of life compared with patients without AHR. In addition, they observed that the patients with the most severe asthma had a greater prevalence of AHR, with a more acute bronchial reactivity, while the sensitivity of the airways $\left(\mathrm{PD}_{20}\right)$ was not altered. ${ }^{11}$ Nevertheless, this study presents an apparent contradiction with our results. Unlike these authors, our data demonstrate that the negative impact of AHR on HROL is not limited to the patients with the most severe asthma given that, in those patients with intermittent or persistent mild asthma, the AOLQ total score maintained a significant relationship with DRS ( $r=-0.796, p<0.001)$, CIR $(r=-0.697, p<0.001)$ and BRI $(\mathrm{r}=-0.819, \mathrm{p}<0.001)$. As our study took into account the therapeutic stage of the patients, the different criteria used to evaluate severity or the known variability in the perception of the severity by either the physician or the patient him/herself ${ }^{30-32}$ could justify this discrepancy at least in part.

The relationship between AHR and HROL could be attributed to a structural disorder of the airways, in such a way that those patients with small airways of a smaller calibre would be more likely to develop a reduction in mid-expiratory flow, which would intensify breathing difficulty or oppression. ${ }^{8}$ However, our results make the existence of a functional disorder more plausible, even in the milder forms of asthma, which cause a rapid and abrupt contraction of the smooth muscle of the airways after having been exposed to a trigger factor. In any case, these results corroborate the idea that an approach for treating asthma based on a strategy for controlling AHR would not only result in an improvement in exacerbations and in less deterioration in lung function over time, as demonstrated by the AMPUL study, ${ }^{29}$ but it could also contribute to an improvement in the HROL of these patients.

The lack of a relationship of AHR with one of the determinats of HROL, respiratory symptoms, ${ }^{9}$ could be attributed to various causes. HROL involves other functional, emotional or social aspects that go beyond mere symptomatic perception. In addition, the poor symptomatic perception of many patients with asthma is well known, as are the limitations of the instruments used to measure respiratory symptoms objectively.

Our study provides other results of special interest. Of the three bronchial reactivity indices analysed, BRI shows the closest relationship with HROL (table 3). It has previously been shown to discriminate better than DRS or CIR between subjects with or without asthma with AHR. ${ }^{19}$ It is possible that the BRI's closer to normal distribution confers on it a greater discriminating capacity when compared with the other indices of bronchial reactivity.

Lastly, our data show that the inspiratory parameters of the spirometry, especially $\mathrm{FIV}_{1}$, maintain a significant contribution to the HROL of the patients with stable asthma (table 3 ). This finding confers special relevance to the inspiratory portion of the flow-volume curve, which could be of interest in the functional evaluation, not only of the glottis but also of the lower airways. In fact, $\mathrm{FIV}_{1}$ shows a similar reproducibility after interventions than forced expiratory volumes, ${ }^{33}$ seems to be more sensitive than these in the detection of symptomatic improvement induced by bronchial reversibility ${ }^{34}$ and maintains a close relationship with dyspnoea intensity. ${ }^{35}$

In conclusion, bronchial reactivity indices are identified as independent predictors for the HROL of asthma patients. The systematic incorporation of these parameters into the analysis of the bronchial provocation tests could be useful in these patients, especially when taking into account that doing so would not result in an increase in either the cost or time of the test, either for the technician or for the patient.

\section{Competing interests None.}

Ethics approval This study was conducted with the approval of the Research Ethics Committees of Hospital Universitario La Princesa and Hospital Universitario La Paz, Madrid.

Provenance and peer review Not commissioned; externally peer reviewed.

\section{REFERENCES}

1. GINA. Global initiative for asthma. Global strategy for asthma management and prevention. Definition. NHLBI/WHO Workshop Report. 2006. http://www.ginasthma. com.

2. Guyatt GH, Feeny DH, Patrick DL. Measuring health-related quality of life. Ann Intern Med 1993:118:622-9.

3. Moy ML, Israel E, Weiss ST, et al. Clinical predictors of health-related quality of life depend on asthma severity. Am J Respir Crit Care Med 2001;163:924-9.

4. Juniper EF, Guyatt GH, Epstein RS, et al. Evaluation of impairment of health-related quality of life in asthma: development of a questionnaire for use in clinical trials. Thorax 1992:47:76-83.

5. Carranza Rosenzweig JR, Edwards L, Lincourt W, et al. The relationship between health-related quality of life, lung function and daily symptoms in patients with persistent asthma. Respir Med 2004;98:1157-65.

6. Siroux V, Boudier A, Anto JM, et al. Quality-of-life and asthma-severity in genera population asthmatics: results of the ECRHS II study. Allergy 2008;63:547-54.

7. Juniper EF, Wisniewski ME, Cox FM, et al. Relationship between quality of life and clinical status in asthma: a factor analysis. Eur Respir J 2004;23:287-91.

8. Juniper EF. Interpreting quality of life data: should we listen to the patient or the clinician? Ann Allergy Asthma Immunol 2003;91:115-16.

9. Juniper EF, Price DB, Stampone PA, et al. Clinically important improvements in asthma-specific quality of life, but no difference in conventional clinical indexes in patients changed from conventional beclomethasone dipropionate to approximately half the dose of extrafine beclomethasone dipropionate. Chest 2002;121:1824-32.

10. Riccioni G, Dòrazio N, Dillio $\mathrm{C}$, et al. Bronchial hyper-responsiveness and quality of life in asthmatics. Respiration 2003;70:496-9.

11. Porsbjerg C, Rasmussen $\mathrm{L}$, Nolte $\mathrm{H}$, et al. Association of airway hyperresponsiveness with reduced quality of life in patients with moderate to severe asthma. Ann Allergy Asthma Immunol 2007;89:44-50. 
12. Orr LC, Fowler SJ, Lipworth BJ. Relationship between changes in quality of life and measures of lung function and bronchial hyper-responsiveness during high-dose inhaled corticosteroids treatment in uncontrolled asthma. Am J Respir Med 2003:2:433-8

13. Millqvist $\mathbf{E}$, Löwhagen 0 , Bende M. Quality of life and capsaicin sensitivity in patients with sensory airway hyperreactivity. Allergy 2000;55:540-5.

14. Wijnhoven HA, Kriegsman DM, Hesselink AE, et al. Determinants of different dimensions of disease severity in asthma and COPD: pulmonary function and health-related quality of life. Chest 2001;119:1034-42.

15. Perpiñá M. Hiperrespuesta bronquial en el asma. Patogenia y medición. Arch Bronconeumol 2004;40(Suppl 5):8-13.

16. Joos GF, O'Connor B. Indirect airway challenges. Eur Respir J 2003;21:1050-68.

17. O'Connor G, Sparrow D, Taylor D, et al. Analysis of dose-response curves to methacholine. An approach suitable for population studies. Am Rev Respir Dis 1987:136:1412-17.

18. Burrows B, Sears MR, Flannery EM, et al. Relationships of bronchial responsiveness assessed by methacholine to serum lgE, lung function, symptoms, and diagnoses in 11-year-old New Zealand children. J Allergy Clin Immunol 1992;90:376-85

19. García-Río F, Mediano 0, Ramírez M et al. Usefulness of bronchial reactivity analysis in the diagnosis of bronchial asthma in patients with bronchial hyperresponsiveness. Respir Med 2004;98:199-204.

20. Ramirez M, García-Río F, Viñas A, et al. Relationship between exhaled carbon monoxide and airway hyperresponsiveness in asthmatic patients. J Asthma 2004;41:109-16.

21. Global Initiative for Asthma 2002. Up-date from: global strategy for asthma management and prevention NHLBI/WHO workshop report 1995. Bethesda, MD National Institute of Health, 2002. (DHHS publication no. (NIH) 02-3659).

22. Sanjuás C, Alonso J, Sanchís J, et al. Cuestionario de calidad de vida en pacientes con asma: la versión española del Asthma Quality of Life Questionaire. Arch Bronconeumol 1995:31:219-26.
23. American Thoracic Society. Standarization of spirometry. 1994 update. Am J Respir Crit Care Med 1995;152:1107-36.

24. Quanjer $\mathbf{P H}$, Trammeling GJ, Cotes JE, et al. Lung volumes and forced ventilatory flows. Eur Respir J 1993:6(Suppl 16):5s-40s.

25. Sterk PJ, Fabbri LM, Quanjer PH, et al. Airway responsiveness. Standardized challenge testing with pharmacological, physical and sensitizing stimuli in adults. Eur Respir J 1993;6(Suppl 16):53s-83s.

26. Cockcroft D, Davis B. Direct and indirect challenges in the clinical assessment of asthma. Ann Allergy Asthma Immunol 2009;130:963-9.

27. Carbone R, Luppi F, Monselise A, et al. Bronchial hyperresponsiveness in asthmatic adults: a long-term correlation study. Eur Rev Med Pharmacol Sci 2005:9:125-31.

28. Cockcroft DW, Berscheid BA. Slope of the dose-response curve: usefulness in assessing bronchial responses to inhaled methacholine. Thorax 1983;38:55-61.

29. Sont JK, Willems LN, Bel EH, et al. Clinical control and histopathologic outcome of asthma when using airway hyperresponsiveness as an additional guide to long-term treatment. The AMPUL Study Group. Am J Respir Crit Care Med 1999;159:1043-51.

30. Colice GL. The seduction of asthma severity categorization. Chest 2003;124:2054-6.

31. Baker KM, Brand DA, Hen J. Classifying asthma: disagreement among specialists Chest 2003:124:2156-63.

32. Prieto L, Badiola C, Villa JR, et al. Asthma control: do patients' and physicians' opinions fit in with patients' asthma control status? J Asthma 2007:44:461-7.

33. Taube C, Kanniess F, Grönke L, et al. Reproducibility of forced inspiratory and expiratory volumes after bronchodilatation in patients with COPD or asthma. Respir Med 2003;97:568-77.

34. Taube C, Lehnigk B, Paasch K, et al. Factor analysis of changes in dyspnea and lung function parameters after bronchodilation in chronic obstructive pulmonary disease. Am J Respir Crit Care Med 2000;162:216-20.

35. Schneider A, Dinant GJ, Maaq I, et al. The added value of C-reactive protein to clinical signs and symptoms in patients with obstructive airway disease: results of a diagnostic study in primary care. BMC Fam Pract 2006;7:28.

\section{Lung alert}

\section{Can procalcitonin have a role in reducing antibiotic selective pressure?}

This multicentre, prospective, parallel group randomised trial compared the use of a modified previously published procalcitonin-guided algorithm for antibiotic use with the conventional use of local or national guidelines for antibiotic use over seven intensive care units. A total of 307 patients in the procalcitonin group and 314 in the control group were included. In the intervention group, a decrease in the procalcitonin level by $\geq 80 \%$ or a fall to $<0.5 \mu \mathrm{g} / \mathrm{l}$ was used as a guide to stopping antibiotics.

At days 28 and 60, mortality in the intervention arm seemed to be non-inferior to that in the control arm. The procalcitonin group had a $23 \%$ lower number of days (mean 10.3 days) on antibiotics compared with the control group (13.3 days; $p<0.0001)$. However, this trial did not find any difference in length of inpatient stays between the groups. The final clinical decision for a patient's selection and commencement or completion of antibiotics in either group lay with the physician-in-charge, irrespective of guidelines or procalcitonin concentration, and this led to the algorithm not being followed in $53 \%$ of patients in the procalcitonin arm. Relative cost-benefits/disadvantages were not discussed.

This study demonstrates that the use of a procalcitonin-guided strategy for treatment with antibiotics in non-surgical patients may well reduce length of antibiotic use and thereby reduce antibiotic selective pressure, with potential benefits in considering the emergence of multiresistant strains with no apparent adverse outcomes, but further studies to rule out potential adverse effects are needed.

Bouadma L, Luyt CE, Tubach F, et al. Use of procalcitonin to reduce patients' exposure to antibiotics in intensive care units (PRORATA trial): a multicentre randomised controlled trial. Lancet 2010;375:463-74.

\section{S Pomfret}

Correspondence to Dr S Pomfret, Core Medical Trainee, Homerton University Hospital, London E9 6SR, UK; suzanne.pomfret@homerton.nhs.uk 